\section{Magnetic Nanoparticles-Supported Platinum Nanoparticles}

platinum

magnetic nanoparticles

ionic liquids

hydrogenation<smiles>CO[SiH2]CCCn1ccnc1</smiles>

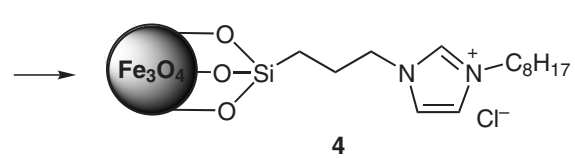

4

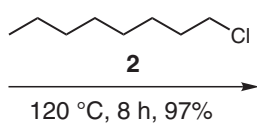

$(\mathrm{MeO})_{3} \mathrm{Si} \curvearrowright \mathrm{N}_{\mathrm{N}}^{+}-\mathrm{C}_{8} \mathrm{H}_{17}$
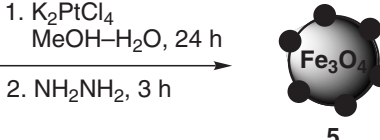

$=\mathrm{Pt}$

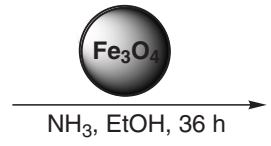<smiles>C(#Cc1ccccc1)c1ccccc1</smiles><smiles>O=C/C=C/c1ccccc1</smiles>

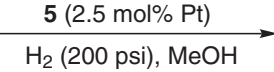

$90{ }^{\circ} \mathrm{C}, 16 \mathrm{~h}$

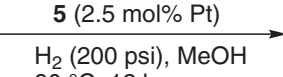

$90{ }^{\circ} \mathrm{C}, 12 \mathrm{~h}$

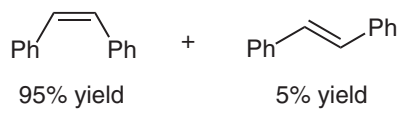

(2)<smiles>OC/C=C/c1ccccc1</smiles>

(3)

$99 \%$ yield
Significance: Platinum nanoparticles supported by magnetic nanoparticles that were modified with ionic liquid were prepared and applied to the selective hydrogenation. Thus, imidazole $\mathbf{1}$ reacted with octyl chloride $\mathbf{2}$ at $120^{\circ} \mathrm{C}$ to give the imidazolium chloride $\mathbf{3}$ in $97 \%$ yield (eq. 1). Treatment of $\mathbf{3}$ with the magnetic nanoparticles, $\mathrm{Fe}_{3} \mathrm{O}_{4}$, in the presence of ammonia afforded ionic liquid modified $\mathrm{Fe}_{3} \mathrm{O}_{4}$ 4. Anion exchange reaction of $\mathbf{4}$ with $\mathrm{K}_{2} \mathrm{PtCl}_{4}$ followed by reduction with hydrazine provided the supported platinum nanoparticles $\mathbf{5}$. The hydrogenation of diphenylacetylene was carried out in the presence of $2.5 \mathrm{~mol} \%$ of catalyst $\mathbf{5}$ under $200 \mathrm{psi}$ of hydrogen at $90^{\circ} \mathrm{C}$ for $16 \mathrm{~h}$ to give cis-stilbene as a major product in 95\% yield (eq. 2). Cinnamaldehyde was chemoselectively hydrogenated under similar reaction conditions to afford 3-phenylprop-2-en-1-ol in 99\% yield (eq. 3).
Comment: The modification of $\mathrm{Fe}_{3} \mathrm{O}_{4}$ with ionic liquid is important for successful formation of the platinum nanoparticles on the surface of the magnetic nanoparticles. Without the modification with ionic liquid, the formation of platinum nanoparticles took place outside the surface of the magnetic support. In the selective hydrogenation of diphenylacetylene, the catalyst can be separated from the reaction mixture by an external magnet and reused four times without significant loss of catalytic activity $\left(1^{\text {st }}\right.$ use: $100 \%$ conv., cis/trans = 95:5; $2^{\text {nd }}$ use: $97 \%$ conv., cis/trans $=92: 5 ; 3^{\text {rd }}$ use: $99 \%$ conv., cis/trans $=93: 6 ; 4^{\text {th }}$ use: $97 \%$ conv., cis/trans $=93: 4$ ). 